\title{
Evaluating Commercial Document Suppliers: Improving Access to Current Journal Literature
}

\section{Alice Duhon Mancini}

This study examines the cost, access mechanisms, services, availability, and reliability of four commercial document suppliers: Faxon Finder, UMI, UnCover, and The Genuine Article. The author examined these suppliers in order to evaluate their ability to assist academic libraries in providing improved access to current journals. Results indicate that commercial suppliers provide preferable turnaround times at sensible prices. The commercial document suppliers studied in this project were able to fill an average of 76.57 percent of the total requests placed. The study found that commercial suppliers cannot replace traditional interlibrary services but do play an important role in an overall document delivery plan.

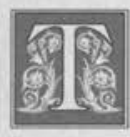

he journal price inflation and flat budgets that academic libraries are experiencing results in cancellations of journal subscriptions. These cancellations stimulate closer evaluation of the quality of services provided by interlibrary loan/document delivery units. The importance of highquality document delivery services becomes intensified in libraries with flat budgets which are unable to keep up with inflation in the publishing industry. Interest in improving turnaround time for document requests and access to journal titles has caused many academic research libraries to evaluate commercial document providers and to define their role in the academic library environment.
The University of Tennessee at Knoxville's (UTK) Interlibrary Services (ILS) unit provides document services to UTK faculty, staff, and students free of charge. During fiscal year 1993-94, ILS received 55,345 requests for lending and borrowing. This was a 20 percent increase over fiscal year 1992-93. UTK participates in OCLC and RLIN interlibrary loan (ILL) networks and, in 1993, became a member of Docline, the National Library of Medicine's ILL network. UTK now orders approximately 25 percent of its article requests from Docline. UTK's turnaround time for borrowing requests, from the day received in the ILS department to the time delivered to patron, is about two weeks. Concern for reducing turnaround time

Alice Duhon Mancini is the Cooperative Information Services Librarian at the University of Tennessee at Knoxville (UTK); e-mail: amancini@utk.edu. At the time of this paper, the author was the Interlibrary Services Librarian at UTK. The author wishes to thank several colleagues for their support and assistance while completing this project: Gayle Baker, Jeff Barry, Marie Garrett, Linda Phillips, and Carol Tenopir. 
and the need to cope with the dramatic increase in business, partly as a result of improved bibliographic access from electronic indexes, caused the author to investigate additional document supply alternatives.

At the same time, UTK Collection Development librarians, along with their counterparts at other universities, sought new access options for patrons when a requested journal could not be purchased because of high subscription prices. As stated by MaryLou Goodyear and Jane Dodd, economic and political factors are affecting library collections nationwide: "Libraries have moved from a situation of budgetary stability to one of budget

\section{The author selected providers with broad coverage because of the wide variety of types of requests received by the ILS unit.}

inventiveness." ${ }^{11}$ Library Journal's "Periodical Price Survey 1995" predicts a 14.5 percent overall price increase in arts and humanities titles, a 16.1 percent overall price increase in social science titles, and a 16.6 percent overall price increase in science titles for $1996 .^{2}$ Libraries have been forced to move from owning materials to accessing materials on a just-in-time basis. ${ }^{3}$ Just as Colorado State University reported in a March 1994 study, the UTK libraries are looking for "creative solutions to meeting the research need to identify and obtain journal articles." 4

Many commercial document suppliers provide table-of-contents services in addition to document delivery. Utilizing commercial suppliers' table-of-contents services in conjunction with their document delivery services is viewed as a possible alternative to purchasing subscriptions. Further, commercial suppliers offer the possibility for users to order articles on a self-serve basis.

The UTK Collection Development Team and library selectors have a particu- lar interest in access to journals that have been canceled and to titles with subscription prices that exceed the limits of the serials budget. To respond to the UTK community's need for access to these journals, ILS is experimenting with supply options that will result in more expedient delivery.

Librarians are evaluating the role of commercial suppliers in the UTK academic environment. Selection criteria for evaluating these suppliers include: (1) number of titles in their collections, (2) reputation, (3) cross-disciplinary nature of their coverage, and (4) willingness to set up a deposit account necessary to participate in this study. ${ }^{5}$

For a three-month period, the author evaluated several commercial document suppliers. She designed the study to help decision makers answer the following questions:

- Are commercial document delivery suppliers' services necessary in an academic library setting?

- What special services do commercial document delivery suppliers offer that enhance access to titles not locally held?

- Which suppliers are the most appropriate for the University of Tennessee?

- Can commercial document services be integrated into traditional ILL units?

\section{Method}

UTK selected the following suppliers for this study: University Microfilms Incorporated (UMI) $(15,000$ titles), Institute for Scientific Information's The Genuine Article (TGA) $(7,000$ current titles and 3,500 retrospective titles), Carl's UnCover $(16,000$ titles), and Faxon Finder $(11,000$ titles). The author selected providers with broad coverage because of the wide variety of types of requests received by the ILS unit. The author established deposit accounts with UMI $(\$ 2,000)$, TGA $(\$ 3,000)$, UnCover $(\$ 3,000)$, and Faxon Finder $(\$ 500)$. She began utilizing these special accounts on September 12, 1994, 
and continued through December 15, 1994.

The selected commercial suppliers provided access to current titles only (with the exception of TGA), thus this study did not deal with the totality of journal requests received by the UTK ILS department, but only those requests from 1990 to the present. The criteria used for selecting articles to be ordered from commercial suppliers were as follows: (1) item was not held by UTK libraries; (2) item was not accessible via electronic full-text databases; and (3) item was not available through Docline. The UTK libraries' ILS unit orders all medicine-related titles through Docline. As the project proceeded, the author slightly altered the criteria and ordered several medicine-related articles from commercial suppliers instead of through the Docline system. This was necessary to increase sample size.

The study tested several hypotheses: (1) commercial document suppliers offer quicker turnaround time than the ILS 14day average; (2) commercial suppliers offer cost-effective service and improved access to titles that some academic libraries cannot afford to purchase or have been forced to cancel; (3) the reproduction quality of commercial documents is acceptable; (4) suppliers would offer easy access and ordering without unnecessary procedures; (5) academic libraries need commercial suppliers' services to supplement ILL document-ordering services; and (6) the ease of use of table-of-contents services, which offer direct-article ordering, provides enhanced access to important titles not held by the library.

The author ordered articles from the selected commercial suppliers in various ways. Faxon and UnCover have only one ordering method. Users must telnet to the database and utilize the table-of-contents services and select the desired articles from the table of contents. UMI allows direct ordering via fax, phone, $\mathrm{ABI}$ Inform on Dialog, and OCLC. TGA allows direct ordering via phone, fax, telnet, Datastar, OCLC, DIMDI, and ISM. For the simplicity of this study, all orders for UMI and TGA were faxed directly to the company and indicated the preferred delivery method on the order form.

Statistics kept for this project included the number of days between ordering and receipt of document for both fax and U.S. mail delivery. The author also kept statistics on the cost of each article and evaluated electronic- and fax-ordering mechanisms provided by the commercial suppliers. She recorded data on the commercial suppliers' ability to fill requests from their published list of titles. In addition, she noted the customer service attitude of each commercial document supplier employee encountered during the study and judged the quality of the copies received. The last major category of data collection was staff time utilized to process requests in comparison to traditional ILL ordering methods. Calculation of staff time was subjective because individual requests take differing amounts of time to process; therefore, the author collected data on any additional procedures that are not part of traditional interlibrary loan methods, such as sorting and scanning paper title lists.

\section{Results \\ Availability of Articles}

Each of the suppliers produces paper lists of the titles from which it fills requests. The author checked these published title lists to verify availability from the suppliers prior to ordering 100 percent of the articles in this study. The suppliers were able to fill a total of 76.57 percent of the requests submitted. The reasons given for not supplying a request included canceled subscriptions, publisher forbids copying, and "cannot supply." Low order numbers for Faxon may be attributed to the fact that many of the Faxon titles were not among those requested by ILS users. The author spent much effort and 


\begin{tabular}{|lcccc}
\hline \multicolumn{5}{c}{ TABLE 1 } \\
Fill Rates for Commercial Suppliers \\
\hline \hline Supplier & \# ordered & \# received & \# unfilled & \% filled \\
\hline Faxon & 17 & 6 & 11 & 35.29 \\
UMI & 52 & 50 & 2 & 96.16 \\
TGA & 39 & 21 & 18 & 53.85 \\
UnCover & 67 & 58 & 9 & 86.57 \\
\hline
\end{tabular}

Total filled during project $=135$

Total requested during project $=175$

time trying to find articles to order from Faxon Finder but was unsuccessful (see table 1).

Fill rates, cost, and turnaround time are good ways to evaluate document delivery providers. Commercial suppliers' filled percentages vary greatly from supplier to supplier. UMI and UnCover had high fill rates, 96.15 and 86.57 percent, respectively, and were usually able to provide what they advertised. Faxon and TGA had much lower fill rates, 35.29 and 53.85 percent, respectively, and had difficulty providing items from their current title list. The author conducted further analysis regarding the citations unfilled by suppliers. She determined whether the unfilled titles represented a certain subject area or were produced by the same publisher (see table 2). She found that the articles seemed to be distributed evenly in several subject areas. Results showed no subject patterns or publishing similarities. Each unfilled title was produced by a different publisher, with the exception of Elsevier, which published two of the unfilled titles. These data show no specific trends relating to commercial suppliers' ability to provide services.

\section{Cost}

Cost analysis is crucial when considering the use of commercial services. Some of the types of administrative costs incurred to provide and obtain interlibrary loans include: search fees, staff time, copy costs, telecommunications charges, and postage. Many ILL
Staff members attempt to obtain as many items as possible from these reciprocal libraries. Academic institutions usually operate with a fixed budget, so taking steps that may cause cost increases must be evaluated prior to decision making. In 1990 , the average cost among ARL members to borrow an item through ILL was \$18.62; the average cost to lend an item through ILL was $\$ 10.93$. The total cost including borrowing and lending was $\$ 29.55$. $^{6}$ The ARL average includes administrative overhead. These statistics show that traditional ILL services are costly for both borrower and provider.

A sample of 200 invoices from UTK's February 1995 ILL invoices shows that the average charge per article borrowed was $\$ 7.59$. This is only an average of those articles UTK was billed for and does not include those received from reciprocal libraries, nor does it include any administrative overhead. The article charges for the document suppliers in this study do not include administrative overhead.

Some commercial suppliers, such as UMI, charge a flat fee for document services (see tables 3 and 4). Others, such as TGA, Faxon, and UnCover, charge a base

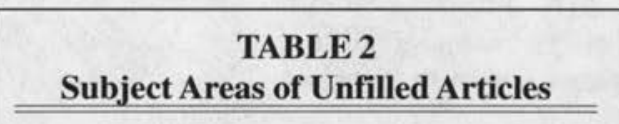

Subject Percent Unfilled

Science-Tech./Medicine 32

Social Science/Educ.

Business/Marketing 
fee plus a copyright fee determined by the publisher. Copyright fees can be quite high. The highest copyright fee encountered during this study was $\$ 23$ for a single article.

Faxon and UnCover offer fax delivery only; UMI and TGA offer fax, express mail, and regular mail delivery options. The author recorded costs for fax delivery and regular mail delivery for this project because these are the methods of delivery currently used by UTK's ILS staff.

Table 3 shows the charges for fax delivery from the four suppliers surveyed in this study. Some suppliers that offer delivery options charge an additional fee for fax delivery. UnCover and Faxon, which deliver only by fax, have a higher base rate. Immoderate copyright fees attached to specific articles caused the highest article charges of this study. The issue of publisher copyright fees is important when selecting suppliers because each supplier has a different pricing schedule. Some suppliers charge the copyright fee directly back to the patron, and some, like UMI, charge a flat fee and equalize the copyright fees across the board. Although some of the article charges found in this study were high, the averages were not necessarily prohibitive.

\section{Turnaround Time}

Turnaround time is a traditional measure used to evaluate quality of service in ILL departments. The average turnaround time for an article to go through UTK's ILS system is thirteen days. One additional day is added for processing and delivery, equaling fourteen days.

The higher numbers for turnaround time by UMI and TGA are because the suppliers did not mail the article to the address given on

the order form. Instead, they mailed the article to another address attached to the account code. One of the purposes of this study is to begin to explore end-user document delivery options. The addressing issue might create potential problems if individual patrons placed orders directly using an ILS account number.

Low average turnaround times for the commercial suppliers suggest that the additional charge for commercial delivery is justified. Average fax delivery for all suppliers was between one and three days (see table 5). Average U.S. mail delivery was five to six days, which is an improvement over UTK's average interlibrary turnaround time (see table 6).

\section{Staff Time}

ILL procedures at the University of Tennessee are delegated among staff and student assistants. Because of the large volume of requests $(55,345$ in 1993-94), routine procedures such as processing, pulling paperwork, and keeping statistics are largely completed by students. Other, more complex parts of the process are performed by staff. The routine is much like

\begin{tabular}{|lccccc}
\hline \multicolumn{5}{c}{ TABLE 4 } \\
Cost & Per Article for Mail Delivery \\
\hline & Faxon & UMI & TGA & UnCover \\
\hline \hline Average & - & $\$ 9.75$ & $\$ 19.83$ & - \\
High & - & $\$ 9.75$ & $\$ 33.65^{*}$ & - \\
Low & - & $\$ 9.75$ & $\$ 11.25$ & - \\
\hline
\end{tabular}

*This high number is due to a $\$ 23.99$ copyright fee placed on the Elsevier title Water Science and Technology. TGA's average, excluding articles from Water Science and Technology, is \$18.51. 


\begin{tabular}{|lllll|}
\hline \multicolumn{5}{c|}{ TABLE 5 } \\
Arrival Time for Fax Articles (in days) \\
\hline \hline & Faxon & UMI & TGA & UnCover \\
\hline Average & 1.72 & 2.63 & 2.82 & 3.25 \\
High & 6 & 7 & 3 & 7 \\
Low & $0^{*}$ & 1 & 2 & $0^{*}$ \\
\hline $\begin{array}{l}\text { *0 indicates articles received on the same day the order was } \\
\text { placed. }\end{array}$
\end{tabular}

suppliers to place holdings on OCLC, would make it easier for ILL staff to incorporate commercial suppliers into existing routines.

These problems are by no means insurmountable. If commercial suppliers such as UnCover and Faxon are added to UTK's list of suppliers, procedures and work flow would

a machine. Each step in the process for each system (OCLC, RLIN, Docline, and electronic full-text retrieval) is assigned to an individual.

Methods for tracking orders are unique for each commercial supplier. The processes for placing and tracking multiple requests from commercial document suppliers are not part of the routine at the UTK ILS department. The only suppliers currently being selected are those that have their holdings on OCLC. Therefore, the tracking mechanism is identical to that of a traditional interlibrary loan. These OCLC suppliers are used only as a last resort because the author assumed frequent use would lead to cost increases.

Many ILL units charge fees for their services, and most charge added fees for rush or fax service.

During this study, differences in tracking and ordering mechanisms caused an increase in the staff time required to manage items ordered from commercial suppliers. This is because procedures for these new systems were not part of the established work flow.

Of the four suppliers chosen for this study, only two, UMI and TGA, have their holdings in OCLC. In order to verify availability from UnCover and Faxon, the author scanned paper title lists supplied by the vendor. This procedure was more time-consuming than searching OCLC. A better method, such as scanning a local electronic database or encouraging all need to be reorganized. Utilizing commercial suppliers also would require developing a more efficient way of verifying which supplier holds which titles. This reorganization would be similar to the procedural changes initiated when an interlibrary loan unit adds a new system to its current list of ILL systems. For example, many procedural changes resulted when UTK added Docline to its list of ILS systems. After just a few weeks, the staff incorporated the necessary procedural changes into the regular work flow.

\section{Access Options}

Suppliers offer a variety of methods for accessing their titles and services. UMI and TGA allow fax ordering and provide paper lists or catalogs of titles held. Both also provide request options through OCLC's FirstSearch and Dialog. UnCover offers free public access to its database through the Internet. UnCover does not accept fax or mail requests but does deliver by fax only. UnCover users may set up deposit accounts or use credit cards. Faxon requires institutions to set up a deposit account with password-protected access to its database and ordering system. After the account is set up, Faxon clients may telnet or set up a dedicated line with Faxon search software. UTK libraries' interest in evaluating the table-of-contents services and end-user ordering features provided by these commercial suppliers led to the librarian's brief analysis of the table-ofcontents services available for TGA, UMI, Faxon, and UnCover. 
The librarian evaluated the table-ofcontents order systems used by Faxon and UnCover, and compared the basic features to OCLC's ContentsFirst database. ContentsFirst, an OCLC FirstSearch database, offers access to the FirstSearch "Order" option, of which UMI and TGA are suppliers. Each of these three services offers title and issue browsing, keyword searching, and onscreen instructions, and is available through the Internet. The main difference between these services is that Faxon and UnCover allow patrons to order items that are not listed in the table-of-contents databases, whereas ContentsFirst does not.

\section{Quality}

The author judged the quality of fax copies to be acceptable to good. The only complaints received from patrons were for fax copies from journals that had text printed on photographs. Poor quality cannot be prevented in this situation. There was no significant difference in quality from vendor to vendor.

The author also judged the quality of photocopies to be acceptable to good. The best quality documents received were tearsheets from TGA. If the original contains complex graphics, tearsheets can be the most effective method for the patron to obtain a high-quality copy.

\section{Conclusions}

Document suppliers provided a better turnaround time than the traditional ILL methods used by UTK. Although suppliers are not always as quick as they advertise, five days for mail delivery is a considerable improvement over fourteen days. This is good news for ILL departments trying to speed up turnaround time. However, all article delivery cannot be replaced by commercial suppliers, because they generally provide access to current journal literature only. TGA's retrospective journal ac- cess is limited to scientific titles. Commercial supplier fees are higher than UTK's ILS department normally pays but are not prohibitive (see tables 2 and 3 ).

The discrepancy between services that commercial suppliers advertise and those they actually provide needs to be noted. The inclusion of titles from which publishers do not allow photocopying is misleading to users of these services. Commercial suppliers' filled percentages vary greatly from supplier to supplier. This is certainly an indication of the currency of the suppliers' lists of available titles. It also is a copyright issue. Some publishers do not allow photocopying of articles; therefore, when tearsheets have been sold, the articles are unavailable. This generally means that tearsheets only are allowed. These limitations are not made clear by the commercial suppliers.

Another discrepancy found is the suppliers' inconsistency in fulfilling the promised 24-hour fax turnaround time. None of the suppliers tested consistently fulfilled this promise, but the average fax delivery times were all within one to three days (see table 5). Although some interlibrary lenders can provide equivalent turnaround times and immediate fax delivery, service is at times inconsistent because of staff shortages and equipment problems. All ILL units are not equivalent, and many are not set up to provide immediate delivery. Sending requests for current journal titles to commercial document suppliers may help to get the documents in the patrons' hands more quickly.

\begin{tabular}{|lrrrr}
\hline \multicolumn{5}{c}{ TABLE 6 } \\
\multicolumn{4}{c}{ Arrival Time for Mail Articles (in days) } \\
\hline \hline & Faxon & UMI & TGA & UnCover \\
\hline Average & $-*$ & 5.74 & 5.76 & $-*$ \\
High & - & 20.00 & 16.00 & - \\
Low & - & 3.00 & 3.00 & - \\
\hline
\end{tabular}

*Faxon and UnCover deliver by fax only. 
Although commercial suppliers consistently offer faster turnaround time than traditional ILL methods, there are some limitations. Document suppliers should be evaluated individually by each library prior to selecting a provider. The services that combine ordering with table-of-contents services give an enhanced level of access different from bibliographic databases. Users may view this enhanced level of access as a viable alternative to purchasing that title. Each commercial supplier provides different services and modes of access to different groups of titles. Requests for specific journal titles vary from library to library depending on the degrees offered by that institution. Re-

\section{A better method, such as scanning a local electronic database or encour- aging all suppliers to place holdings on OCLC, would make it easier for ILL staff to incorporate commercial suppliers into existing routines.}

quests also vary depending on the specific research needs of the faculty, staff, and students. This study shows that the services and titles offered by UMI and UnCover coincide with the needs of the UTK ILS unit.

\section{Future of Document Delivery}

This study shows commercial document suppliers to be a viable supplement to traditional ILL activities. Utilizing commercial suppliers may give ILL departments more document access options without placing an unfair burden on any one library. Commercial suppliers seem to be particularly helpful when ordering multiple articles from a specific journal. UTK also is interested in the potential to provide self-service delivery to patrons who need rush services. Brown University's "Express" delivery service is one example of self-service, customer-paid document service. ${ }^{7}$ Because the author found the delivery and access mechanisms to be acceptable, further investigation in setting up these services can now proceed. If usage of commercial suppliers increases at UTK, cost-reduction options are available. Some suppliers, such as TGA, offer volume discounts for ordering a certain number of articles per year. This can be advantageous for all parties.

Using multiple commercial document suppliers presents some unique problems. One of the difficulties is being able to access title lists quickly and efficiently. A related problem is figuring out an efficient way to decide which titles will be ordered through which suppliers and which titles will be ordered through interlibrary loan. The two methods available for ILS to verify whether a title is held by a commercial supplier are: (1) searching OCLC (if a supplier lists its holdings), and (2) wading through paper title lists or scanning online lists. One solution to these problems is to create a local database that merges these different types of data. At the University of Tennessee Libraries, the Networked Services Team is developing a database called Mockingbird (accessible through the World Wide Web). Mockingbird mimics other journal resources but contains more information specific to UTK's holdings and document needs. The database links journal titles and abbreviations with ISSNs to other information such as preselected location strings for those titles available from reciprocal libraries. Other crucial data to be included in the future are availability from document suppliers and full-text online availability, including Dialog file numbers and FirstSearch full text. The longrange plan is to link Mockingbird to the catalog so users can obtain the most upto-date, complete holdings information. Another facet of the long-range plan is to link Mockingbird to CD-ROM products held by libraries so that users can verify UTK's holdings and receive information on the availability of titles not held by UTK. Mockingbird has tremendous potential value for many library functions, 
including interlibrary loan, collection development, acquisitions/serials, and reference.

As a result of the findings of this study, the author recommended expanded use and continued evaluation of commercial suppliers. Similar to the conclusions in
Wayne Pederson and David Gregory's November 1994 article, commercial suppliers cannot replace traditional ILL, but they can enhance the productivity and flexibility of current services and increase user access to many necessary titles. ${ }^{8}$

\section{Notes}

1. MaryLou Goodyear and Jane Dodd, "From the Library of Record to the Library as Gateway: An Analysis of Three Electronic Table-of-Contents Services," Library Acquisitions: Practice \& Theory 18 (Mar. 1994): 253-64.

2. Lee Ketcham and Kathleen Born, "Serial vs. the Dollar Dilemma: Currency Swings and Rising Costs Play Havoc with Prices," Library Journal 120 (Apr. 1995): 43-49.

3. Goodyear and Dodd, "From the Library of Record," 253.

4. Elizabeth A. Fuseler, "Providing Access to Journals-Just in Time or Just in Case?" CERL News (Mar. 1994): 130-32, 148.

5. Scott Stebelman, "Analysis of Retrieval Performance in Four Cross-Disciplinary Databases: Article1st, Faxon Finder, UnCover, and a Locally Mounted Database," College \& Research Libraries 55 (Nov. 1994): 562-67.

6. Marilyn M. Roche, ARL/RLG Interlibrary Loan Cost Study (Washington, D.C.: ARL, 1993).

7. Anne Cerstvik Nolan, "Information Express Is Here," Bibliofile 21 (fall 1993): 3-4.

8. Wayne Pederson and David Gregory, "Interlibrary Loan and Commercial Document Supply: Finding the Right Fit," Journal of Academic Librarianship 20 (Nov. 1994): 263-72.

\section{Elegant Solutions for Preservation}

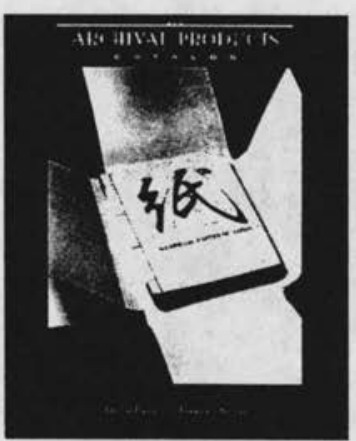

Protective Enclosures

Pamphlet Binders

Music Binders

Bound Four Flap Enclosures

Tan Archival Board

Grey/White Archival Board

Drop Spine Archival Boxes

Academy Folder

Manuscript Folder

2134 E Grand Avenue

Des Moines, Iowa 50305

Call

for a complete

PII. 800.526.5640

FAX 515.262 .6013

catalog 


\section{Thanks for your support}

ACRL thanks these corporate colleagues for their financial support of its activities and programs throughout the year.

\section{Summa Cum Laude (over $\$ 5,000$ )}

Ameritech

Apple Computer, Inc.

Bell Atlantic of Pennsylvania

Carnegie Mellon University's Computing Services \& Univ. Libraries Staff

Chadwyck-Healy, Inc.

EBSCO Subscription Services

Prepnet

\section{Magna Cum Laude $(\$ 1,001-\$ 4,999)$}

Antiquarian Booksellers Association of America

Blackwell North America

Congressional Quarterly

The Faxon Company

Indiana University, Bloomington, School of Library \& Information Science

Information Access Company

Research Publications International

University Microfilms, Inc.

H.W. Wilson Company

Yankee Book Peddler, Inc.

\section{Cum Laude $(\$ 500-\$ 1,000)$}

Baker \& Taylor Books

Biological Abstracts, Inc.

Bromer Booksellers

CARL Corporation \& UnCover Company

Chemical Abstracts Service Division

DBA Lame Duck Books

Elsevier Science, Inc.

Historicana

Institute for Scientific Information

Lena Minkoff Memorial Fund., Inc.

Ken Lopez and Pamela K. Drecler

Midwest Library Service

Elizabeth Phillips

Rulon-Miller Books, Inc.

Thomas Schwartz

SIRSI Corporation

Softline Information, Inc.

Swann Galleries

William Reese Co.

University Archives

Ximenes: Rare Books, Inc. 